\title{
Enactivism and the Paradox of Moral Perception
}

\author{
Janna Van Grunsven ${ }^{1}$ (1) \\ Accepted: 7 September 2021 / Published online: 11 October 2021 \\ (c) The Author(s) 2021
}

\begin{abstract}
In this paper I home in on an ethical phenomenon that is powerfully elucidated by means of enactive resources but that has, to my knowledge, not yet been explicitly addressed in the literature. The phenomenon in question concerns what I will term the paradox of moral perception, which, to be clear, does not refer to a logical but to a phenomenological-practical paradoxicality. Specifically, I have in mind the seemingly contradictory phenomenon that perceiving persons as moral subjects is at once incredibly easy and incredibly difficult; it is something we do nearly effortlessly and successfully all the time without giving it much thought and it is something that often requires effort and that we fail at all the time (also often without giving it much thought). As I will argue, enactivism offers distinctive resources for explaining the paradoxical nature of moral perception. These resources, moreover, bring out two important dimensions of ethical life that are frequently overlooked in contemporary ethical theory: namely the embodied and socio-technical environment-embedded dimensions of moral perception and moral visibility. As I make my argument, I will be connecting enactivism with insights from David Hume's and Iris Murdoch's moral philosophy as well as insights from the field of Epistemic Injustice. As such, I aim to situate enactivism within the larger theoretical ethical landscape; showing connections with existing ethical theories and identifying some of the ways in which enactivism offers unique contributions to our understanding of ethical life. While doing so, I will furthermore introduce two forms of moral misperception: particular moral misperception and categorial moral misperception.
\end{abstract}

Keywords Enactivism $\cdot$ Moral perception $\cdot$ Epistemic injustice $\cdot$ Participatory sense-making $\cdot$ Autism $\cdot$ Bodily normativity $\cdot$ Sociotechnical embeddedness

\section{Introduction}

In this paper I home in on an ethical phenomenon that is powerfully elucidated by means of enactive resources but that has, to my knowledge, not yet been explicitly addressed in the literature. The phenomenon in question concerns what I will term the paradox of moral perception, which, to be clear, does not refer to a logical but to a phenomenological-practical paradoxicality. Specifically, I have in mind the seemingly contradictory phenomenon that perceiving

This work is part of the research programme Ethics of Socially Disruptive Technologies, which is funded by the Gravitation programme of the Dutch Ministry of Education, Culture, and Science and the Netherlands Organization for Scientific Research (NWO grant number 024.004.031)

Janna Van Grunsven

J.B.vanGrunsven@tudelft.nl

1 Delft University of Technology, Jaffalaan 5, 2628 BX Delft, The Netherlands persons as moral subjects is at once incredibly easy and incredibly difficult; it is something we do nearly effortlessly and successfully all the time without giving it much thought and it is something that often requires effort and that we fail at all the time (also often without giving it much thought). As I will argue, enactivism offers distinctive resources for explaining the paradoxical nature of moral perception. These resources, moreover, bring out two important dimensions of ethical life that are frequently overlooked in contemporary ethical theory: namely the embodied and socio-technical environment-embedded dimensions of moral perception and moral visibility. As I make my argument, I will be situating enactivism within the larger theoretical ethical landscape, connecting enactivism with insights from David Hume's and Iris Murdoch's moral philosophy as well as insights from the field of Epistemic Injustice. ${ }^{1}$

\footnotetext{
1 As a number of enactive thinkers-myself included-have already shown, there are indeed numerous ways in which the enactive framework connects with but also disrupts already existing views and assumptions in ethical theory. For instance, in the normative ethical domain, enactivists have highlighted the fruitful connections between
} 
My argument will unfold as follows. I will begin by sketching what I mean with the notion of moral perception (Sect. 2). Confining myself here to the domain of human interaction, I will understand moral perception as the experience of other people as minded intentional affective subjects of experience whose ways of engaging the world and expressing themselves are indicative of psychologically rich experiential lives. ${ }^{2}$ I will then home in on how moral philosophers have reflected both on the effortlessness and the difficulty of moral perception. Specifically, in Sect. 3, I will use David Hume's account of sympathy as a paradigmatic view of ethical life grounded in an effortless automatic perceptual responsiveness to others as moral subjects. While acknowledging what is compelling about Hume's view and bringing out some analogies between Hume's view and enactive approaches to our perceptual orientation towards other people, I will also bring out its limits by building off Trip Glazer's account of emotional misperception, which is developed from an Epistemic Injustice angle (Sect. 4). Glazer's account helps me finetune the notion of moral misperception by detailing the conditions under which our misperceiving another person counts as a moral failure. On the basis of Glazer's account, I furthermore identify one of two forms of moral misperception that I will be working with, namely particular moral misperception. Particular moral misperception, as I call it, occurs when the particular emotions, intentions and experiences expressed by a person are misperceived as a result of "pernicious ignorance" (Glazer 2019; see also Dotson 2011).

In Sect. 5, I widen Glazer's approach, which is focused on particular moral misperception, via Iris Murdoch's account of moral perception. Like Glazer and contra Hume, Murdoch emphasizes not the effortlessness but precisely the difficulty of perceiving other people and the moral work involved in

\section{Footnote 1 (continued)}

enactivism and care ethics (Silverman 2012; Urban 2014, 2015; Anonymous 2018). In the landscape of metaethics and moral psychology, enactivists have challenged commonplace views concerning the source of moral values and the modal separation between actions and desires on the one hand and perception and cognition on the other (Cf. Colombetti and Torrance 2009; Anonymous 2015).

${ }^{2}$ While I focus on our experience of other human beings here, the broad contours of my argument apply to our perceptual experience of non-human animals as well. Though some cases are hard (ticks, mosquitos, etc.), many other living animals confront us with the same paradoxical nature of moral perception (I can often perceive my cats' expressions and the response they afford (stroking them, giving them food) without much effort-and yet there are equally moments where they can become wholly opaque to me). Though cashing this out goes beyond the current focus of my argument, I suspect that widening the notion of moral perception to include our lives with non-human animals would benefit from the strong continuity thesis of mind and life defended by autopoietic enactivists, which presents all living things as sense-making beings occupying a perspective of concern onto a world that matters to them. our perceptual orientation towards others. By building out some of Murdoch's suggestive remarks and drawing links with enactivism I introduce a second form of moral misperception: categorial moral misperception. Whereas particular moral misperception occurs when, as a result of pernicious ignorance, the particular intentions and affects expressed by a person are misperceived, categorial moral misperception signifies a failure to perceive a person as a robustly minded sense-making being tout court.

The contrast between the Humean view, which emphasizes the effortless nearly automatic nature of moral perception, and the 'Glazerian-Murdochian' view, which emphasizes its effortful character, sets the stage for an enactive intervention. As I will show, enactivism has the resources to explain both the effortlessness and the difficulty of moral perception, thus doing justice to the paradoxical phenomenology of moral perception. In order to make my case, I first home in on a concrete case of moral misperception. The case in question, discussed in Sect. 6, concerns the wide-spread moral failure to perceive (some) autistic people as robustly minded persons whose expressive behavior is reflective of a distinct meaningful lived perspective onto the world. The case of autism helps me bring out that enactivism can explain both the difficulty and effortlessness of moral perception and that it does so by foregrounding the embodied and the embedded dimensions of our perception of other people. Looking at the embodied dimension first, I will, in Sect. 7.1, home in on enactivism's notion of participatory sense-making, bringing out how bodily interaction norms can have a significant effect on the degree to which we perceive someone as a moral subject. Then, in Sect. 7.2, I will look at enactivism's emphasis on the embedded nature of cognition, showing that moral perception is in part shaped by people's shared embeddedness in a sociotechnical environment. These dimensions are often overlooked or discussed merely in passing in accounts of moral perception (and moral agency more generally) but point to important areas where moral misperception can be mitigated.

\section{What is Moral Perception? An Initial Sketch}

As I have been discussing, this paper is about how enactivism can contribute to our understanding of what I call the paradox of moral perception. As such, I should first specify what I mean by moral perception. Among those working in the space of metaethical theory and moral psychology, talk of moral perception may evoke the image of a special moral faculty of intuition that allows a moral agent to grasp what makes something an instance of, say, goodness. Many have argued that this image-delivered to us most prominently by G.E. Moore-presents moral perception as something 
altogether distinct from our "ordinary perception" of everyday things in the world, thus making it seem anti-naturalistic and mysterious. I am inclined to agree with that assessment and I will not be understanding moral perception in this way. Rather, I understand moral perception as the fully ordinary everyday way in which we often succeed, but also often fail, at being perceptually beholden and responsive to the lives of others. When I speak of perceiving people as moral subjects what I have in mind is, broadly speaking, the experience of other persons as minded intentional affective subjects of experience who occupy their own lived perspective onto a shared world and who give expression to their minded lives through a vast range of bodily (and linguistic) expressions. By defining moral perception in this manner it is in many ways in line with how enactivists understand social cognition or participatory sense-making (the enactive term for social cognition). ${ }^{3}$ The reason I am purposely opting for the term moral perception, is to emphasize that I take social cognition or participatory sense-making to be a perceptual orientation towards another person that is ethically-laden from the start (See also Colombetti and Torrance 2009; Dierckxsens 2020).

Let me give an example of what I have in mind. Picture a typical morning-ride on a crowded subway: the doors swing open and a mass of people swarm in. While attempting to secure a spot for yourself you step on someone's toe. You apologize. Apologies accepted. As the doors are about to close, a mother (child under one arm, stroller under another) comes rushing down the stairs. Several people immediately reach for the closing doors. Success. The mother, squeezing herself, her child, and her over-sized stroller onto the train, is met with a mixture of sympathetic and disapproving faces. Someone gets up and offers her his seat. As soon as the train is set in motion the car is filled with the sounds of an A cappella singing group: four middle-aged men, their attire clearly unsuited for the cold winter day, are maneuvering their way through the crowd. While treating us to their Sam Cooke-like arrangement of Blowing in the Wind, they are collecting change in a Styrofoam cup (or attempting to anyways). Some of us reach for our wallet. Most of us fix our eyes on our shoes, "pretending that we just didn't see."

What this everyday scene brings out is that, already in our most basic day-to-day interactions, we typically directly perceive others as the sorts of beings who afford and foreclose different possibilities for action and response (Gibson 1979). I reliably perceive a distinction, say, between my fellow

\footnotetext{
3 The other term often used in the enactive literature to refer to our direct perceptual experience of other people's minded experiential lives is empathy. Because the term empathy means different things in different contexts and because it is employed in a descriptive as well as a normative sense, I have decided to leave out this term altogether for fears that it will muddle the main point of my argument.
}

commuters on the subway and the subway door by perceiving the door and not my fellow commuters as affording to be leaned up against. And in making this perceptual distinction I am implicitly acknowledging my fellow commuters as the sorts of beings whose sense of bodily space matters in a way that directly bears on my actions. It is within the midst of our infinitely rich, contextually varying ways of interacting with others that we perceive them, with varying degrees of success, as beings of a certain kind—namely as minded intentional affective beings who occupy their own lived viewpoint onto a shared world and who afford (and forecloses) particular forms of treatment and response. An ethical space, albeit in a minimal sense, is enacted here. Of course, as I will discuss (and as my example already indicates), this space is always precarious as moral perceptual failures of various sorts are a constant in human life as well. But often times, as I first want to bring out in some more detail, moral perception operates in a seemingly automatic effortless manner, carving out a shared social environment in which we often appropriately engage with the expressive bodies of other people.

\section{The Effortlessness of Seeing People as Moral Subjects: Some Humean and Enactive Insights}

One of the first philosophers to offer a systematic treatment of the ways in which human beings are often 'always already' perceptually caught up in each other's lives, affected by one another's lived experiences, was David Hume, whose account of sympathy presents our basic relationship to other people as marked by an automatic attunement that is at once perceptual-cognitive and affective. ${ }^{4}$ In Hume's words:

The minds of all men are similar in their feelings and operations; nor can any one be actuated by any affection, of which all others are not, in some degree susceptible. As in strings equally wound up, the motion of one communicates itself to correspondent movements in every human creature. When I see the effects of passion in the voice and gesture of any person, my mind immediately passes from these effects to their causes, and forms such a lively idea of the passion, as is presently converted into the passion itself. In like manner, when I perceive the causes of any emotion, my mind

\footnotetext{
${ }^{4}$ There is a tension here between what I see as Hume's hybrid account of sympathy (straddling cognitive and affective states) and the standard reading of Humean metaethics, which treats perception and cognition as evaluatively neutral and modally distinct from action-guiding conative states (see Van Grunsven 2015 for an extensive discussion; see also Little 1997).
} 
is convey'd to the effects, and is actuated with a like emotion (2000, 3.3.1.7).

Like "strings equally wound up," we are attuned to each other. And although Hume doesn't have a spelled-out account of embodiment, he clearly works with an image of human bodies as expressive, as resonating with each other, such that "tis certain" that we perceive and are affected by each other's "signs of anxiety and concern" (2000, 3.3.1.7). Very often, we cannot so much as begin to identify another human being without being affectively responsive to their bodily expressivity (to their voices and gestures). Hume saw this perceptual-affective attunement to others as "the chief source of moral distinctions," investing us in the lives, actions and characters of other people and in how those other people are, in turn, invested in us (Hume 2000, 3.3.6; Baier 1991). ${ }^{5}$

In many ways, Hume's phenomenological characterization of sympathy resembles the enactive emphasis on the direct perceptual nature of social cognition. Take, for instance, the following sketch by Shaun Gallagher, who urges that:

We do not try to get into the other person's mind, we try to get into their world, or more precisely, into a world that we already share with them... Ordinarily, in our everyday encounters in the pragmatic and social contexts that characterize our lives, we gain a perceptual grasp of another's contextualized actions, gestures, and expressions, and we understand their speech acts as meaningful and intentional, without looking beyond such meanings to their mental states (Gallagher 2007, 354).

While the primary point of focus in this passage is on the shortcomings of Theory of Mind approaches to social cognition, we can equally highlight its Humean ethical undertones. Gallagher sketches how we (typically) always already share a world together, a world enacted because we (typically) perceive the expressive behaviors of others as meaningful, intentional, and affording interaction. Thus, we often need nothing more than the sight of a face, exhausted or elated or the shrieking sounds of a loved-one in despair in order to respond (perhaps by sacrificing our seat, our day, or even our life as we know it). I want to suggest, much like Hume, that this serves as the soil of ethical life. Ideally, when things go as they should, moral perception unfolds effortlessly, operating in the background and quietly enacting a shared social world in which people are manifest as

\footnotetext{
${ }^{5}$ Hume thought that robustly moral evaluations of people's characters required taking up what he called the General Point of View. For a discussion of how our taking up of this perspective is motivated by sympathy see Van Grunsven 2015, Chapter 1.
}

persons who matters. We are confronted with the foundational normative role that being morally visible plays in our daily functioning precisely when it breaks down. ${ }^{6}$

Hume doesn't go into detail about how we acquire, sustain, or enrich our capacity for sympathy and this is likely because he treats our sympathetic nature as bedrock. We just happen to be so constituted that we perceive and respond to others as the possessors of rich experiential lives and this is simply another "fact about ... ourselves to be acknowledged" (Smith, 1994, 8). What Hume does believe is that although "tis certain" that sympathy will run its course whether we want to or not, it is enlivened when there is a closer resemblance between us and the target of sympathy:

resemblance must very much contribute to make us enter into the sentiments of others, and embrace them with facility and pleasure. Accordingly, we find, that where, beside the general resemblance of our natures, there is any peculiar similarity in our manners, or character, or country, or language, it facilitates sympathy. ...The sentiments of others have little influence when far remov'd from us, and require the relation of contiguity [and causation] to communicate themselves entirely (Hume 2000, 2.1.11).

According to Hume's empiricist philosophy of mind, the relations of resemblance, contiguity, and causality, are principles of association that mechanically bind together the impressions and impression-based ideas that get formed in our minds. As such, Hume views sympathy as a mechanism that runs its course automatically and involuntarily. By contrast, while enactivists might endorse the phenomenology of Hume's account of sympathy, the resources enactivists rely on in explaining social cognition in its effortless nearly automatic moments, mark an important point of departure from Hume with clear ethical implications. To anticipate, our direct perceptual experience of others is quietly mediated by embodied interaction norms and our embeddness in sociotechnical practices and structures, pointing to two often overlooked realms for mitigating moral perceptual failure, or so I will argue.

\section{Particular Moral Misperception: When Effortless Moral Perception Breaks Down}

Since, for Hume, sympathy is a principle that seems to establish an automatic involuntary connection between ourselves and others that happens to be more vividly and deeply entrenched when those others are contiguously closer

\footnotetext{
${ }^{6}$ In this sense the logic of moral perception resembles the logic of trust (Cf. Baier 1986; Anonymous 2020b).
} 
or more similar to us, it seems by itself ill fitted to guide us in our moral lives. Indeed, Jesse Prinz who for the most part embraces a Humean approach to moral psychology, rejects Hume's idea of sympathy as a precondition for ethical life, arguing instead that sympathy is "by and large bad for morality" as it "seems to be intrinsically biased." Because sympathy's "proper objects are ... individuals," Prinz wagers that it has an "intrinsic dark side," that makes it an unsuitable "tool for morality. We can no more overcome its limits than we can ride a bicycle across the ocean; it is designed for local travel" (Prinz 2011, 229).

While I agree with Prinz's warning that Hume is overly confident in sympathy as providing an automatic foundation for moral life, I worry that Prinz throws out the proverbial baby with the bathwater while kicking the can down the road. For one thing, the dyadic close-personal settings in which sympathy allegedly reverberates with ease according to Hume and Prinz, are themselves the locus of instances of moral success and moral failure. Take, for instance, the complexities of a marriage between two white hetero-sexual cisgendered individuals with similar political convictions. Most if not all of the conditions for successful sympathy seem to be met here. And yet one individual can find himself to be consistently misperceived by his partner in a manner that constitutes as a moral failure. Let me expand on this idea, while also offering a more precise account of when something counts as an instance of moral misperception, via Trip Glazer's account of emotional misperception and the conditions under which it does "epistemic violence" to the person whose emotional expressions are misperceived (2019).

Glazer works within the field of Epistemic Injustice, which has helped identify the countless ways in which people can be silenced or deprived of resources they need (and should reasonably expect to have access to) in order to successfully relate to themselves and others as the knowing, meaning-expressing, sense-making beings that they are (Cf. Fricker 2007; Medina 2017; Congdon 2017). While the emphasis within the Epistemic Injustice field has been on linguistic forms of epistemic harm, Glazer argues that "our facial expressions, gestures, and tones of voice convey a great deal of information about ourselves, much of it about what we are currently experiencing. These acts of nonlinguistic communication are no less susceptible to being silenced, distorted, and exploited" (59). Building off Kristie Dotson's account (2011), Glazer proposes that emotional misperception constitutes as an instance of epistemic violence when one person misreads another person's "nonlinguistic expression of emotion" as a result of "pernicious ignorance" (60). Pernicious ignorance is ignorance that causes "harm" in the person misperceived and that "follows from a predictable epistemic gap in cognitive resources"
(Dotson 2011, 238). ${ }^{7}$ What I will be arguing towards the end of this paper, is that our moral perception of others is quietly shaped by implicit embodied interaction norms and the norms and values entrenched into the sociotechnical structures that we are embedded in. Because of their quiet unthematic normativity, these sites of embodied interaction and sociotechnical embeddedness are precisely sites where predictable epistemic gaps can be accrued. Thus, raising awareness about the effects of these sites on moral perception can help fill predictable epistemic gaps in our cognitive resources, thus making us more responsible in our perceptual relations to other people.

The three forms of reliable ignorance that Glazer himself focuses on are:

(1) Emotion stereotyping, where "a false generalization creates expectations about which emotions a person will or will not express in a given context, and these expectations can skew the observer's perception" (60);

(2) Emotion apathy, where "an observer could invest due care in the reading of someone's emotions, but for lack of trying does not" (61); and,

(3) Emotion parochialism, where "an observer is ignorant of a community-specific style of emotional expression, and so fails to read an expression correctly" (61).

Note that in all of these forms of moral misperception, the failure occurs at the level of what someone's is expressing; one person is, due to some form of reliable ignorance, perniciously misperceiving the meaning (or the "information," to use Glazer's term) of a particular expressed emotion by another person in a manner that causes harm; for instance, members on a hiring committee may mistake a woman's expression of calm confidence for contemptuousness as a result of sexist ideology, resulting in her not being offered the job (to use an example provided by Glazer). I will, from hereon, regard such cases as instances of particular moral misperception. ${ }^{8}$

In all of the cases described by Glazer, pernicious ignorance can, in principle, be worked on, resulting in a change in moral perception and a mitigation of moral harm. This

\footnotetext{
${ }^{7}$ Of course, what one ought to know - as a perceiving moral agentand what predictable epistemic gaps in cognitive resources one may be permitted to have, depends on the epistemic resources one can reasonably expect to have access to, which, in turn, is dependent on contextual situational and personal factors (Dotson 2011).

${ }^{8}$ While Glazer focuses on emotion expressions and the conditions under which their misperception constitutes as a form of epistemic violence, I take his formal account of when something counts as an instance of morally harmful misperception as generally applicable to our perceptual responsiveness to other people's bodily expressed lived perspective.
} 
kind of labor and its effects on moral perception are overlooked both within Hume's own view, which sees our perceptual-affective attunement to the lives of others as providing an automatic bedrock foundation for ethical life, and within Prinz's critique of Hume, which presents moral perception as an oxymoron as he takes our affective-perceptual sensitivity towards others to be intrinsically biased. As such, notions of moral progress, moral failure, moral development, and moral responsibility have no place in the domain of perception on the Humean view (Van Grunsven 2015).

Iris Murdoch, by contrast, spent much of her life as a philosopher situating those notions precisely at the heart of our perceptual relation to the world, arguing that people can temporarily or permanently lose their visibility as moral persons and that we can fail to see particular others in ways that count as instances of moral failure. Because I believe her account is a clear representative of the view that perception is the site of difficult moral labor and because I believe Murdoch's writings on the difficulty of moral perception help bring out an additional form of moral misperception that isn't articulated by Glazer, I will now have a brief look at her account, explicating some of its links with enactivism along the way.

\section{Categorial Moral Misperception: Murdoch and Enactivists on the Difficulty of Seeing People Aright}

When ethical theorists aim to identify the locus of moral agency, there is a common tendency to focus almost exclusively on choice and action viewed as modally distinct from perception and cognition. Iris Murdoch spent much of her career as a moral philosopher articulating the insufficiency of this choice-action view, insisting that how we bring in view the lives of other people "is morals too" $(1998,73)$. On Murdoch's view (1998) which "connects morality with attention to individuals, human individuals or individual realities of other kinds" (329) the moral agent is marked by a "progressive attempt to see a particular object clearly," which she views as "an endless task" for which "we must claim responsibility" (317).

Much like Glazer's claim that our perceptions of others can become harmfully skewed as a result of "a false generalization" (60), Murdoch urges that there "is ... 'distorted vision" "and that we can be tempted into "building up convincingly coherent but false pictures of the world" (Murdoch 1998, 329). And much like Glazer, who speaks of pernicious misperception as a result of a failure to "invest due care" in how we perceptually attend to someone, Murdoch speaks of the importance of loving attention, which she views as a mode of perception through which we are genuinely responsive to someone in their particularity $(1998,370)$.
In addition to her epistemic focus on how we can succeed (and fail) as perceiving moral agents, Murdoch also points to ontological reasons for the difficulty of perceiving people aright. People, she stresses, are entities of a peculiar sort; ethical theory needs "a renewed sense of the ... opacity of persons," (Murdoch 1998, 293). In spelling out what it is that we attend to when we are involved in the ongoing labor of being perceptually responsive to people as the opaque entities that they are, Murdoch introduces the somewhat illusive notion of a person's "texture of being:"

When we apprehend and assess other people we do not consider only their solutions to specifiable problems, we consider something more elusive which may be called their total vision of life, as shown in their mode of speech or silence, their choice of words, their assessments of others, their conception of their own lives, what they think attractive or praiseworthy, what they think funny: in short the configurations of their thought which show continually in their reactions and conversation. These things ... constitute what ... one may call the texture of a man's being or the nature of his personal vision (Murdoch 1998, 81)

I understand this Murdochian insight as aligned with enactive insights regarding the phenomenology of experiencing other people "as they are" (Reddy 2008, 29). Enactivist avant la lettre Maurice Merleau-Ponty (2012), for instance, describes how our perception of other people marks an experience of a "an open life" (370), adding that the "other body is ... the place of a certain elaboration and somehow a certain "view' of the world" (369); "a center of actions which radiate over a "milieu" and which ought to be perceived as "a certain silhouette in the physical and in the moral sense (Merleau-Ponty 1963, 156-7, my italics). The idea here, is that when we perceive another embodied person we not only perceive (or misperceive) the particular meanings to which they give bodily expression at any given time; we also perceive (or misperceive) them as the site of ongoing sense-making as such. Thus, accurately seeing another person isn't (just) about accurately perceiving their particular emotions, desires, intention, or concerns (and combatting forms of ignorance that tend to skew such accurate perception). It is also to perceive them as full-blooded expressive individuals as such; individuals whose particular actions, expressions, turns of phrase, and styles of interacting with the world must be placed within their "total vision of life" as the sense-making beings that they are. Enactivists maintain that it is through interacting with others that we experience them in the fullest sense as the sense-making beings that they are (Reddy 2008; Anonymous 2018). When we interact, we experience the felt demand to frequently "readjust $[\mathrm{t}]$ [our] ... individual sense-making activities," to the other person, altering our expressions and "actions contextually 
in order to reencounter the other," whose sense-making, in turn, "modulate my own" (De Jaegher and Di Paolo 2007, 504). To reinvoke Murdoch, perceiving another aright is thus an endless task because in the domain of human interaction and perception, the perceiver "constantly influences the other by his actions and vice versa," such that perceiving and interacting with another person are "interdependent, and there is no pregiven other" (Fuchs and De Jaegher 2009, 469).

In the previous section we saw with Glazer that there are various ways in which we can be guilty of instances of particular moral misperception. I now want to add that we can also misperceive someone at a more fundamental level, namely as the center of "an open [sense-making] life" tout court. I call this categorial moral misperception. Following Glazer's proposal, I will maintain that when categorial misperception stems from pernicious ignorance it constitutes as an instance of moral misperception.

How exactly particular and categorial moral misperception can come apart or blend together in our ethical lives is a question that goes beyond the scope of this paper. What I do want to discuss now is that there is at least one case where these two forms of moral misperception tend to coalesce. The case in question concerns the ways in which typically developed people (or neurotypicals) often misperceive autistic people in a moral sense. Looking at this case serves a dual purpose in my argument. Firstly, as I just mentioned, it helps brings out how moral perception can fail not only at the particular but also at the categorial level. Secondly, a number of enactivists have tried to explain the breakdown in what I call moral perception as it occurs in the context of neurotypicals perceiving autistic persons. Looking at these enactive proposals offers a targeted lens for (1) explaining the paradox of moral perception and (2) identifying overlooked areas where pernicious ignorance can be accrued but also, by the same token, where moral perceptual failure can be mitigated.

\section{Moral Misperception: the Case of Autism}

As I sketched in Sect. 3, enactivists by and large agree with Hume's phenomenology of sympathy, which foregrounds the direct perceptual effortlessness with which human beings are often attuned and responsive to one another in their everyday lives. In Gallagher's words: "we see or more generally perceive in the other person's bodily movements, facial gestures, eye direction, and so on, what they intend and what they feel' $(2004,204)$." But the perception of "the other person's body" as the locus of clearly identifiably "opportunities for action and expressive behavior" seems to lose its "automatic, irresistible" character when we turn our attention to how autistic persons and neurotypicals-i.e. 'typically' developed cognitive agents-often perceive and respond to one another (Gallagher and Hutto 2008, 4). Much emphasis has been placed on the perceptual difficulties that autistic people experience in the arena of social cognition. Consider, for instance, the following passage in which Oliver Sacks characterizes the challenges that autistic author and engineer Temple Grandin faced as a child in the area of social cognition:

Something was going on between the other kids, something swift, subtle, constantly changing - an exchange of meanings, a negotiation, a swiftness of understanding so remarkable that sometimes she wondered if they were all telepathic. She is now aware of the existence of these social signals. She can infer them, she says, but she cannot perceive them, cannot participate in this magical communication directly (Sacks 1995, 273, my italics).

More recently, neurodiversity activists and researchers alike have highlighted that this perceptual breakdown actually goes both ways; many autistic people move and express themselves and attend to the world in ways that are reflective of meaningful sense-making, but that remain perceptually opaque to neurotypicals (Cf Milton 2012; McGeer 2009; Sasson et al. 2017). Take 'stimming' or 'self-stimulatory behavior,' which many autistics engage in and which can take on a variety of forms: humming, grunting, rocking, flapping, spinning, finger flipping, etc. Stimming is often seen as merely pathological stereotypical behavior-behavior that isn't communicative, expressive, or thoughtful. But if we look at personal testimonies and recent community based participatory research, what emerges is a much richer perspective on stimming. For instance, for autistic blogger and activist Mel Baggs, stimming can signify an embodied immersive form of sense-making, through which their environment is explored and brought to life in a rich tactile manner (2007). A recent study also reveals that fine-grained bodily differences in how a person stims can reliably convey crucially different emotional states:

Emotional valence may shape the specific form that the same general behaviour takes. For example, several participants explained that they flap their hands both when excited or happy as well as when distressed, and two (Alana and Ethan) detailed that hand flapping due to positive states involves hands open and arms out in a waving-like motion, unlike hands and arms kept further down towards oneself (when in a more negative state) (Kapp et al. 2019).

Because particular stims may reliably express a particular emotion, Kapp et al. suggest that (at least sometimes) stimming "may have effectively communicated the person's 
feelings (and those close to them may come to understand this meaning)" (2019). Attentive neurotypicals can perceive and be responsive to the meanings expressed through stimming as a form of sense-making if "due care" is taken, such that a person's "specific style of emotional expression" isn't reliably misperceived (Glazer 2019, 61). Indeed, Kapp et al. bring out the harm experienced by autistic people when, due to reliable ignorance, their environment silences their stimming or when, for fear of stigmatization, they selfsilence: "Participants described feeling a variety of resentful emotions ... including anger, nervousness, frustration, belittlement, shame and confusion. ... Many wished to avoid drawing negative attention and, in response to feeling marginalised, attempted to suppress their stims in public," despite the fact that stimming can provide autistic people with an important self-regulatory coping resource when "their sensory and social surroundings" are experienced too "intensely" (Kapp et al. 2019).

As we saw with Murdoch, human beings are marked by an ineluctable opacity. She believes that this opacity affords a constant perceptual-cognitive engagement with another person's texture of being. But the opacity of autistic expressivity as frequently experienced by neurotypicals has not typically motivated a stance of loving attention; a willingness to take up the endless task of seeing the autistic other. This is in part attributable to one of the most standard theories of autism, namely the Theory of Mind Deficit view [or ToMD]. According to ToMD, the minds of autistic people are marked by an allegedly damaged or absent Theory of Mind mechanism, which is thought to enable people to understand their own behavior as well as the behavior of others as caused by mental states such as beliefs, desires, intentions, emotions (Baron-Cohen 1995; Frith \& Happé 1999). Some versions of ToMD have gone so far as to suggest that autistic persons altogether lack introspective awareness of themselves and an awareness of others as minded beings; that an autistic person is "a dead soul in a living body" (Walter Spitzer, cited in Silberman 2015, 431). This scientifictheoretical stance is both reinforced by and reinforcing of the perception of autistic idiosyncratic bodily behavior as nonexpressive and non-communicative (Anonymous 2020a). By naturalizing autistic persons as marked by a deficient Theory of Mind and maintaining that they are as a matter of scientific fact "dead souls in a living body," we reliably fail to see autistic persons as the "the center of an open life," as a sense-making "meaningful life" tout court.

This whole-sale discrediting of autistic people's lives as psychologically thick is, I wager, a paradigmatic instance of categorial misperception: it goes deeper than misperceiving how, say, a particular form or instance of stimming is expressive of a particular feeling, emotion, or concern. It affects how the autistic person is perceived in a categorial sense, which, historically, has resulted in a wide range of dehumanizing actions (Silberman 2015). Too often, what is in fact a form of categorial moral misperception has been mistaken for a scientifically backed form of perception that is appropriately responsive to what autistic minds are allegedly like (see also Van Anonymous 2020a; Anonymous and Roeser 2021). The availability of widely proliferated testimonials from autistic persons undermining this view makes this form of categorial moral misperception particularly troubling; the resources for closing the reliable cognitive gap that is contributing to our misperception of autistic people's rich experiential expressive lives are clearly within the scope of responsible moral perceptual agency.

\section{The Paradox of Moral Perception: An Enactive Perspective}

We have seen that the phenomenology of our perceptual relation to others is of a paradoxical character; perceiving people as moral subjects is both something we effortlessly succeed at all the time and something that requires work and that we fail at all the time. When moral perception unfolds in its effortless successful manner, an ethical space in which we perceive and respond to one another as the sense-making beings we are is enacted. When instances of particular moral misperception take place, the precariousness of this ethical space and our tenuous visibility as moral subjects is brought to the surface. When categorial moral misperception takes place, people can find themselves wholly outside the ethical space that is continually enacted through people's ongoing perceptual responsiveness to one another. We need an account of our perceptual relationships to other people that can explain both the effortlessness of moral perceptual success and the difficulties and failures of moral perception. In this final section I will present enactivism as that theory.

The first step is to focus on moral perception in its effortless moments, i.e. those moments when we appropriately and directly perceive and respond to other people's expressed experiential lives. As I have argued elsewhere, the term direct perception is somewhat misleading here, for from an enactive viewpoint our direct perceptual world-directedness is thoroughly mediated (Anonymous 2020a). This work of mediation unfolds at various different levels; our perceptual experience of the world is shaped by our needs, skills, habits and interaction styles as bodily beings, by the conceptual skills we develop over the course of our life, by the actions and interaction processes we are engaged in, and by the environment in which we are embedded (Cf. Noë 2004). My focus in what follows is on (1) the mediating role that our embodiment and our embeddedness in a sociotechnical environment plays in enabling effortless perceptual responsiveness to other people qua moral sense-making subjects and (2) how such effortless direct perception can break down as a 
consequence of these domains of mediation. I will continue to take the case of autism as paradigmatic and illustrative.

\subsection{The Role of Embodiment in Our Experience of Others as Moral Subjects}

In Sect. 5, we saw that enactivists propose that we see others as the sense-making beings that they are in the fullest sense through engaging with them. It is in engagement that we have a felt sense of the other as a sense-making being, who continually demands that I readjust and modulate my own sense-making in order to keep them in view. If I respond appropriately to the demands that the other's sense-making body confront me with, keeping her in view as the expressive sense-making being she is, what emerges is a relational space of meaning enacted through coordinated interaction, also termed participatory sense-making (De Jaegher and Di Paolo 2007). Enactivists have detailed the crucial role that our embodiment plays in processes of participatory sensemaking. As developing infants, what we acquire through interaction is a range of embodied interaction skills, equipping us with "pre-reflective knowledge of how to deal with others-how to share pleasure, elicit attention, avoid rejection, re-establish contact" (Fuchs and De Jaegher 2009, 481). Additionally, this embodied know-how for engaging others and facilitating mutual understanding, involves a fine-grained perceptual attunement to the other's expressive body (their pitch and tone of voice, the ways they make eye contact, exhibit posture, style and temporality in movement, etc.) and to the embodied relational properties of human interaction (e.g. the rhythm of turn-taking).

When things go well and our bodily skills, styles, and expectations are more or less in sync, this supports our being effortlessly visible to the other as the sense-making expressive beings that we are. By the same token, disruptions at this level of embodied coordinated interaction can, to varying degrees, detrimentally affect how we perceive one another. ${ }^{9}$

\footnotetext{
${ }_{9}^{9}$ Breakdowns in coordinated interaction don't necessarily threaten our visibility to others as moral subjects. As Fuchs \& De Jaegher point out "miscommunications are normal events; they occur when one of the partners fails to appreciate the meaning of the other's emotional display and in turn reacts inappropriately" (Fuchs \& De Jaegher, 2009, 479). Furthermore, interactional breakdown affords each interactor with new ways of re-establishing connection, breakdown is essential for the development and mastering of interaction skills (see De Jaegher \& Di Paolo 2007; Reddy, 2008). As I have been arguing, it is when "one of the partners fails to appreciate the meaning of the other's emotional display and in turn reacts inappropriately" as a result of pernicious ignorance that it counts as an instance of moral misperception.
}

As Hanne de Jaegher has argued, the mutual misperceptions occurring in autistic-neurotypical interactions often stem from different trajectories in sensorimotor skilldevelopment and different rhythms and styles in embodied sense-making, leading to "hampered participatory sensemaking" (2013). Now, while, according to De Jaegher's account, this breakdown in perceptual responsiveness and participatory-sense-making occurs as a result of mismatches between autistic and neurotypical forms of embodied sensemaking, it is at the same time important to note that there is a normative asymmetry here. As discussed in Sect. 6, neurotypicals have a longstanding track-record of attributing what De Jaegher presents as relational mismatches to deficiencies within the autistic person. Whereas neurotypical styles and norms of bodily expressivity and comportment may often be perceived as opaque by autistic people, autistic people's styles and norms of bodily expressivity and comportment are perceived not just as opaque but also as meaningless; as indicative of lives lacking in psychological depth and significance. This reveals that neurotypical embodied sensemaking has a normativity built into it that is often taken for granted, where 'our' ways of attending to the world and soliciting attention to others and our styles of embodied expressivity are implicitly taken as the right ways.

To bring out the dominant normativity that is often built into embodied participatory sense-making, we can consider the challenges that nonspeaking people confront when using high-tech augmentative and alternative communication technologies [AAC] to express themselves and engage in communicative exchange with others (Cf. Anonymous and Roeser 2021). Many of the embodied stylistic dimensions of interpersonal interaction and communication that most of us take for granted are unavailable to AAC-users. Appropriately timed turn-taking, direct eye-contact, and crucial stylistic and tonal forms of self-expression (sounding "sensitive or arrogant, assertive or humble, angry or happy, sarcastic or sincere, matter of fact or suggestive and sexy") are difficult if not possible to achieve (Portnuff 2006). The ability to introduce such stylistic nuance into one's communicative interactions is not only crucial for full self-expression; it also shapes one's perceived authenticity and authority as a speaker. Indeed, AAC-user Colin Portnuff questions whether 'typical' communicators can look past the homogeneity of his AAC-mediated expressions and see him in his individuality and uniqueness.

Erin Manning (2016) argues that the implicit embodied norms embedded in dominant forms of participatory sensemaking quietly marginalize "all unbounded, unpredictable, rhythmic, insurgent life" (5). While "remain[ing] for the most part in the background of our everyday lives" neurotypical norms of embodiment quietly and perniciously shape “our idea of which lives ... are worth living” (Manning 2016, 
5). ${ }^{10}$ The unreflective needs to become an explicit area of reflection so that people have resources to take responsibility for the perceptual failures that can emerge from the space of dominant embodied normativity. Without such explicit reflection, implicit dominant norms of embodied interaction will remain a persistent source of epistemic ignorance capable of skewing our perception of others in morally harmful ways. ${ }^{11}$ If enactivism is right that our perceptual experience of the world and of others is mediated by our skills, habits, and concerns, then taking up such reflection, and disrupting old norms and habits of embodied interaction, can loop back into how we experience the sense-making lives of those who have fallen prey to moral misperception, particular or categorial.

\subsection{The Role of Embeddedness in Perceiving Others as Moral Subjects}

I just argued that our effortless perceptual experience of other people as moral subjects is mediated by embodied skills, rhythms, and expectations. People who are out of sync with dominant ways of participatory sense-making are at a heightened risk of falling prey to particular or even categorical moral misperception. What I want to bring out in this final section is how our quiet embodied normative assessment of other people's embodied expressions and styles is, in turn, environmentally embedded, where our human environment is profoundly shaped by shared sociotechnical structures and institutions. Employing Gallagher and Crisafi's (2009) concept of mental institutions, Joel Krueger and Michelle Maiese (2018) explicate how our ability to reliably make sense of other people is partially off-loaded onto the wider sociocultural and material environment we inhabit, where mental institutions refer to the "rich networks of norm-governed practices, artifacts, and traditions that shape how we attend to and interact with the world and others" (2018, p 10). ${ }^{12}$ The notion of mental institutions helps explain how those who inhabit the same

\footnotetext{
${ }^{10}$ Erin Manning sees the implicit bodily disruption of neurotypical norms of embodiment-a disruption that stimming is, for instance capable of-as an ethical-political event enabled by what she terms the minor gesture:

11 See Van Goidsenhoven and De Schauwer (2020) for an account of how a reflective awareness and inhibition of neurotypical norms of temporality in interaction can create "openings in fixed normative relations to voice and communication that all the time exclude and marginalize persons labelled as non-verbal (331).

12 As an anynomous reviewer rightfully pointed out, the term 'mental institution' is unfortunate in this context. As I am developing my argument from within the $4 \mathrm{E}$ tradition and as this term has been put forth within this tradition I have kept it here. However, the notion of sociotechnical imaginaries (Jasanoff 2015) could play a similar role in the argument I am making.
}

sociotechnical structures (and whose normative expectations at the level of embodied participatory sense-making are aligned), often directly perceive, with great nuance and specificity, what another person's bodily expressions mean. For instance, when I visit the hospital for a medical checkup, it is to an important degree because of my familiarity with this sociotechnical mental institution-with the actions afforded by check-in counters, elevators, waiting rooms, physician scales, blood pressure monitors-that I effortlessly navigate this shared social environment and that I directly perceive the various gestures and actions of the receptionist, visitors, nurse practitioner, and physician with whom I interact in their immediate, distinct, and appropriate sense (I directly perceive the physician's subtle nod towards the scale as an invitation to undress in order to begin the medical examination). By the same token, my ability to routinely respond to the affordances characteristic of the hospital qua sociotechnical mental institution make me visible to others as someone who 'belongs'. Echoing the earlier testimony from AAC-User Colin Portnoff, an autistic AAC-user shares the challenges she faces to be seen as an independent capable patient when navigating health care settings: "I have used my Alphasmart [portable communication device] when my speech is too slow or difficult to understand for medical appointments. Some of the doctors have been really great, but others have acted really condescending when I used it, also immediately assuming I couldn't be alone, had to have had parents there too ..." (Nicolaidis et al. 2015).

Krueger and Maiese too bring out how mental institutions imbue our perceptual experience of others with a thoroughly normative-evaluative dimension:

For those operating within a mental institution, 'certain models of expectancy come to be established, and the patterns, which over time emerge from these practices, guide perception as well as action.' ... Many aspects of social understanding are ... carried by the world, scaffolded by the norms and routines that regulate our embodied interactions and habits of mind, and which have their social significance built into them.... Understanding others involves bringing shared norms to bear, for our sense of what people generally do and what they can be expected to do is linked to our views about what they ought to do (2018, 21, my italic).

As Krueger and Maiese have furthermore argued, the normative-evaluative dimension that mental institutes infuse into our experience of others (how we perceive and attend to them and how we interact with them), helps explain why neurotypicals are prone to misperceive the idiosyncratic expressive behavior of autistic person's, taking it as markers of deficiency (of something not going as it 'ought' to) rather than as alternative forms of sense-making. In their words, autistic "'habits of mind,' 'often fail to mesh smoothly with 
neurotypical [mental] institutions" $(2018,13)$. We should be mindful that "social impairments" typically "confined to the head of the individual with ASD," in fact "includ[e] environmental features: neurotypical institutions that lack the flexibility and inclusivity needed to responsively mesh with ASD habits of mind' $(2018,29)$.

In a world increasingly shaped by sociotechnical mental institutions, it is of prime importance that we attend to the ways in which technological artefacts and sociotechnical mental institutions can promote or thwart our perceptual experience of others; how it accommodates or silences the expressive behaviors of some and not others. Much like Manning, who worries that neurotypical norms of embodied sense-making quietly shape whose lives we perceive as meaningful, Ashley Shew argues that the space of technology development and the manners in which we imagine human well-being through the lens of technological innovation, often reflect an ableist outlook onto the world. Ableism, with its "preference, explicit or not, for bodies and minds that are nondisabled ... shapes our expectations and perceptions. These preferences (which may be obvious or subtle) ... are made manifest in the built environment" (Shew 2020, 41) Take, for instance, the AAC devices that I have discussed in passing. Depending on their design, these devices can both (1) enforce neurotypical communication norms that limit autistic self-expression and that materialize a vision of autistic expressive bodily life as deficient and, (2) help enact a social interaction space in which nonspeaking autistic persons can manifest themselves and be seen as persons whose particular (sometimes idiosyncratic) ways of engaging the world and expressing themselves are indicative of psychologically rich meaningful experiential lives (for an extensive discussion of this see Van Grunsven and Roeser 2021).

Technology's ability to embed norms and values into our shared environment, shaping how we perceive and value the lives of others, lead Langdon Winner to propose that "the issues that divide or unite people in society are settled not only in the institutions and practices of politics proper, but also, and less obviously, in tangible arrangements of steel and concrete, wires and transistors, nuts and bolts" $(1980,128)$. In much the same way that our embodied interaction norms often remain in the background, we also tend to skip over the mediating cognition-supporting role that our built environment plays (that is, of course, when the built environment works for us). If this is right, then ethical theory should start paying close attention not only to the enactive theory of embodied participatory sense-making that can help us become more sensitive to the normativity of embodied interaction and its effects on moral perception, but also to theories in ethics of technology that foreground the need for a value-sensitive developing and embedding of technology (Cf. Verbeek 2011; Van den Hoven et al. 2015). To rephrase
Murdoch, how we give shape to the built environment "is morals too."

\section{Conclusion}

I have argued that enactivism can explain the paradox of moral perception, doing justice to our everyday experience that perceiving people aright is both effortless and difficult, something we succeed at and something we fail at all the time. In explaining the paradox from an enactive perspective, I furthermore revealed two domains often overlooked in ethical theory that, if attended to, can help identify important areas for mitigating moral misperception. Our moral perception of others is quietly shaped by implicit embodied interaction norms and the norms and values entrenched into the sociotechnical structures that we are embedded in. Because of their quiet unthematic normativity, these sites of embodied interaction and sociotechnical embeddedness are sites where predictable epistemic gaps can be accrued. Raising awareness about the effects of these sites on moral perception can help fill predictable epistemic gaps in our cognitive resources, thus making us more responsible in our perceptual responsiveness to the lives of others.

Open Access This article is licensed under a Creative Commons Attribution 4.0 International License, which permits use, sharing, adaptation, distribution and reproduction in any medium or format, as long as you give appropriate credit to the original author(s) and the source, provide a link to the Creative Commons licence, and indicate if changes were made. The images or other third party material in this article are included in the article's Creative Commons licence, unless indicated otherwise in a credit line to the material. If material is not included in the article's Creative Commons licence and your intended use is not permitted by statutory regulation or exceeds the permitted use, you will need to obtain permission directly from the copyright holder. To view a copy of this licence, visit http://creativecommons.org/licenses/by/4.0/.

\section{References}

Baggs M (2007) In my language. https://www.youtube.com/watch?v= JnylM1hI2jc

Baier AC (1986) Trust and anti-trust. Ethics 96(2):231-260

Baier AC (1991) A progress of sentiments: reflections on hume's treatise (First printing edition). Harvard University Press, Cambridge

Baron-Cohen S (1995) Mindblindness: an essay on autism and theory of mind. MIT Press, Cambridge

Colombetti G, Torrance S (2009) Emotion and ethics: an inter-(en) active approach. Phenomenol Cogn Sci 8(4):505-526

Congdon M (2017) What's wrong with epistemic injustice? Harm, vice, objectification, misrecognition. In IJ Kidd, J Medina, G Pohlhaus (eds.), The Routledge Handbook of Epistemic Injustice, pp 243-254

De Jaegher H (2013) Embodiment and sense-making in autism. Front Integr Neurosci 7(15):1-19. https://doi.org/10.3389/fnint.2013. 00015 
Dierckxsens G (2020) Enactive cognition and the other: enactivism and levinas meet halfway. J French Francoph Philos 28(1):100-120

Dotson K (2011) Tracking epistemic violence, tracking practices of silencing. Hypatia 26(2):236-257

Fricker M (2007) Epistemic injustice: power and the ethics of knowing. Oxford University Press, Oxford

Frith U, Happé F (1999) Theory of mind and self-consciousness: what it is like to be autistic? Mind Lang 14(1):1-22

Fuchs T, Jaegher HD (2009) Enactive intersubjectivity: Participatory sense-making and mutual incorporation. Phenomenol Cognit Sci 8(4):465

Gallagher S (2004) Understanding Interpersonal problems in autism: interaction theory as an alternative to theory of mind. Philos Psychiatry Psychol 11(3):199-217

Gallagher S (2007) Simulation trouble. Soc Neurosci 2(3-4):353-365

Gallagher S, Crisafi A (2009) Mental institutions. Topoi 28(1):45-51

Gallagher S, Hutto DD (2008) Understanding Others through primary interaction and narrative practice. In: Zlatev J, Racine T, Sinha C, Itkonen $\mathrm{E}$ (eds) The shared mind: perspectives on intersubjectivity. John Benjamins, pp 17-38

Gibson JJ (1979) The ecological approach to visual perception. Houghton Mifflin, Boston

Glazer T (2019) Epistemic violence and emotional misperception. Hypatia 34(1):59-75

Hume D (2000) A treatise of human nature. Oxford University Press, Oxford

Jasanoff S (2015) Future imperfect: science, technology, and the imaginations of modernity. In: Jasanoff S (ed) Dreamscapes of modernity-sociotechnical imaginaries and the fabrication of power. The University of Chicago Press, Chicago

Kapp KS, Steward R, Crane L (2019) People should be allowed to do what they like: autistic adults views and experiences of stimming. Autism 23(7):1782-1792

Krueger J, Maiese M (2018) Mental institutions, habits of mind, and an extended approach to autism. Thaumàzein $6: 10-41$

Little MO (1997) Virtue as knowledge: objections from the philosophy of mind. Noûs 31(1):59-79

Manning E (2016) The minor gesture. Duke University Press, Durhan

McGeer V (2009) The thought and talk of individuals with autism: reflections on ian hacking. Metaphilosophy 40(3-4):517-530

Medina J (2017) Varieties of hermeneutical injustice. In Kidd IJ, Medina J, Pohlhaus G The Routledge handbook of epistemic injustice, pp 41-52

Merleau-Ponty M (2012) Phenomenology of perception. Routledge, Abingdon, New York

Milton DE (2012) On the ontological status of autism: the double empathy problem. Disabil Soc 27:883-887

Murdoch I (1998) Existentialists and mystics: writings on philosophy and literature. Allen Lane/the Penguin Press, UK

Nicolaidis C, Raymaker DM, Ashkenazy E, McDonald KE, Dern S, Baggs AE, Kapp SK, Weiner M, Boisclair WC (2015) Respect the way i need to communicate with you": healthcare experiences of adults on the autism spectrum. Autism Inter J Res Pract 19(7):824-831. https://doi.org/10.1177/1362361315576221

Noë A (2004) Action in perception. MIT Press, Cambridge

Portnuff C (2006) AAC: a user's perspective. Video Lecture, presented at Oregon Health and Science University as part of the AACRERC Webcast series. https://www.youtube.com/watch?v=ldXC3 FbShn0

Prinz J (2011) Against empathy. South J Philos 49:214-233

Reddy DV (2008) How Infants Know Minds. Harvard University Press, Cambridge, Mass

Sasson N, Faso D, Nugent J, Lovel S, Kennedy DP, Grossman RB (2017) Neurotypical peers are less willing to interact with those with autism based on thin slice judgments. Sci Rep. https://doi. org/10.1038/srep40700

Shew A (2020) Ableism, technoableism, and future AI. IEEE Technol Soc Mag 39:40-41

Silberman S (2015) Neurotribes: the legacy of autism and the future of neuro-diversity. Avery, New York

Silverman M (2012) Virtue ethics, care ethics, and the good life of teaching. Action Crit Theory Music Educ 11(2):96-122

Smith M (1994) The moral problem. Blackwell, OXford

Urban P (2014) Toward an expansion of an enactive ethics with the help of care ethics. Front Psychol 5:1354

Urban P (2015) Enactivism and care ethics: merging perspectives. Filozofia 70(2):p119-129

Van Den Hoven J, Vermaas PE, Van De Poel I (eds) (2015) Design for values: an introduction. In: Handbook of ethics, values, and technological design. Springer, Netherlands, pp 1-7. https://doi. org/10.1007/978-94-007-6970-0_40

Van Goidsenhoven L, De Schauwer E (2020) Listening beyond words: swinging together. Scand J Disabil Res 22(1):330-339

Van Grunsven, J. (2015) Bringing life in view: an enactive approach to moral perception. Ann Arbor: University Microfilms, Dissertation, The New School

Van Grunsven, J. (2018) Enactivism, second-person engagement and personal responsibility. Phenomenol Cognit Sci 17: 131-156

Van Grunsven, J. (2020a) Perceiving 'other' minds: autism, 4E cognition, and the idea of neurodiversity. J Conscious Stud 27(7-8): $115-143$

Van Grunsven, J.(2020b) Perceptual breakdown during a global pandemic: introducing phenomenological insights for digital mental health purposes. Ethics Inf Technol. https://doi.org/10.1007/ s10676-020-09554-y

Van Grunsven, J. \& Roeser S (2021) AAC technology, autism, and the empathic turn. Social Epistemol. https://doi.org/10.1080/02691 728.2021 .1897189

Verbeek PP (2011) Moralizing technology - understanding and designing the morality of things. University of Chicago press

Winner L (1980) Do artefacts have politics. Daedalus 109(1):121-136

Publisher's Note Springer Nature remains neutral with regard to jurisdictional claims in published maps and institutional affiliations. 